\title{
Prader-Willi Syndrome and Growth Hormone Deficiency
}

\author{
Zehra Aycan1,2, Veysel Nijat Baş3 \\ ${ }^{1}$ Dr. Sami Ulus Women Health, Children's Education and Research Hospital, Clinics of Pediatric Endocrinology, Ankara, Turkey \\ 2 Yıldırım Beyazıt University School of Medicine, Department of Pediatric Endocrinology, Ankara, Turkey \\ ${ }^{3}$ Kayseri Training and Education Hospital, Department of Pediatric Endocrinology, Kayseri, Turkey
}

\section{Introduction}

\begin{abstract}
Prader-Willi syndrome (PWS) is a rare multisystem genetic disorder demonstrating great variability with changing clinical features during patient's life. It is characterized by severe hypotonia with poor sucking and feeding difficulties in early infancy, followed by excessive eating and gradual development of morbid obesity in later infancy or early childhood. The phenotype is most probably due to hypothalamic dysfunction which is also responsible for growth hormone (GH) and thyroid-stimulating hormone (TSH) deficiencies, central adrenal insufficiency and hypogonadism. The multidimensional problems of patients with PWS can be managed with multidisciplinary approach. Reduced GH secretion, low peak GH response to stimulation, decreased spontaneous GH secretion and low serum IGF-1 levels in PWS patients have been documented in many studies. GH therapy has multiple beneficial effects on growth and body composition, motor and mental development in PWS patients. The recommended dosage for GH is 0.5-1 mg/ $\mathrm{m}^{2} /$ day. GH therapy should not be started in the presence of obstructive sleep apnea syndrome, adenotonsillar hypertrophy, severe obesity and diabetes mellitus. GH treatment should be considered for patients with genetically confirmed PWS in conjunction with dietary, environmental and life-style measures.
\end{abstract}

Key words: Prader-Willi syndrome, growth hormone deficiency, growth hormone treatment

Conflict of interest: None declared

Received: 03.12 .2013
Accepted: 12.01 .2014
Prader-Willi syndrome (PWS) was first defined in 1956 by Swiss scientists (1). The prevalence of the disease, which is similar in both genders, is between 1/10 000 and 1/30 000 with approximately 400000 PWS patients living worldwide $(2,3,4)$. In previous years, due to morbid obesity and related complications, no patient lived over the age of 50 years, but today, the life span of these patients has increased. PWS is characterized by a recognizable pattern of physical findings with significant cognitive, neurologic, endocrine and behavioral abnormalities caused by lack of expression of genes from an imprinted region of the paternally inherited chromosome 15q11-q13, near the centromere (5). These patients experience difficulty in feeding due to hypotonia in infancy leading to growth retardation, but they become obese after this period due to their uncontrollable craving for food. The degree of obesity increases with age and becomes permanent. Clinical presentation and physical characteristics of PWS show variations among age groups $(2,3,4,5,6,7)$. Since obesity and related complications are important causes of morbidity and mortality in PWS cases, early diagnosis and careful follow-up are of great importance.

Pediatric endocrinologists, using a holistic approach, need to manage the age-related worsening obesity and associated complications in addition to the central hypothyroidism due to hypothalamo-hypophyseal dysfunction, the central adrenal insufficiency, hypogonadotropic hypogonadism and growth hormone $(\mathrm{GH})$ deficiency in PWS patients.

\section{Address for Correspondence}

Veysel Nijat Baş MD, Kayseri Training and Education Hospital, Department of Pediatric Endocrinology, Kayseri, Turkey Gsm: +90 35235122 40/7112 E-mail: veyselnijatbas@gmail.com

OJournal of Clinical Research in Pediatric Endocrinology, Published by Galenos Publishing. 
The present review will focus on the characteristic findings of patients with PWS, with special reference to $\mathrm{GH}$ and $\mathrm{GH}$ treatment.

\section{Clinical Findings}

The clinical signs of PWS vary by age group.

Prenatal period: Decreased fetal activity, polyhydramnios, breech presentation and abnormal position of the hands and feet on ultrasonography in the $3^{\text {rd }}$ trimester (elbows in flexion and feet in dorsi extension) constitute the characteristic findings of PWS in this period of life $(7,8)$.

Infancy: Severe hypotonia, difficulty in feeding due to poor sucking, growth retardation, weak crying, genital hypoplasia (cryptorchidism, scrotal and clitoral hypoplasia), dermal and ocular depigmentation are the main findings $(3,4,6,8)$.

Early childhood: Hyperphagia and obesity (unless food consumption is restricted externally), abnormal body composition (decreased muscular mass, increased fat mass), reduction in resting energy expenditure, short stature, behavior problems (eating-related problems such as hiding food, taking food out of the trash can and stealing food) are the main findings in this age group $(3,4,6)$.

Late childhood and adolescence: Delayed puberty (descent of the testes into the scrotum may be delayed until adolescence in boys, menarche may be delayed sometimes to as late as age 30 years in girls), lack of pubertal height gain, morbid obesity and related complications [e.g. obstructive sleep apnea (OSA) syndrome, cor pulmonale, diabetes mellitus, atherosclerosis, hypertension], osteoporosis, scoliosis $(30 \%)$, behavior problems, epilepsy $(25 \%)$ are the main findings in this age group $(2,3,7)$.

Since PWS is associated with a hypothalamo-hypophyseal function disorder, the patients should be investigated also for central hypothyroidism and hypophyseal adrenal insufficiency at the time of diagnosis. Mental and motor retardation are almost always present and $\mathrm{IO}$ is generally 40 points below the mean values of the population. The diagnosis must certainly be verified by genetic testing in all patients suspected to have PWS. Appropriate follow-up and treatment approaches are important in the patients who are diagnosed genetically. In PWS, regulating the diet, programming exercise and management of endocrinological, neurological and psychological problems in every period of life require a multidisciplinary approach.

\section{GH Deficiency}

Although the prevalence of $\mathrm{GH}$ deficiency in PWS patients changes according to the diagnostic criteria used, it has been reported to be present in $40 \%$ to $100 \%$ of patients $(6,9,10)$. $\mathrm{GH}$ deficiency becomes prominent in the second decade of life in children that have not received $\mathrm{GH}$ replacement. These children fail to show the acceleration in height gain seen in puberty and the mean final height without treatment is $155 \mathrm{~cm}$ in boys and $148 \mathrm{~cm}$ in girls $(2,4,9)$

Since PWS is associated with hypothalamo-hypophyseal dysfunction, $\mathrm{GH}$ secretion is generally reduced in such cases. This is not related to obesity. Unlike obese individuals who show a decrease in $\mathrm{GH}$ secretion while maintaining normal insulin-like growth factor-1 (IGF-1) levels, in PWS patients, IGF-1 levels are also decreased $(11,12)$. The criteria used for normal children can also be used for the diagnosis of growth retardation in these children. Of note, nutrition deficiency and presence of hypothyroidism particularly in infancy should be excluded, since these conditions would influence growth rate. GH deficiency should be considered in children with PWS who show an inadequate growth rate but have no nutritional deficiency or hypothyroidism. Twenty four-hour $\mathrm{GH}$ secretion is inadequate in 58\%-100\% of PWS patients $(12,13,14,15)$. While a low growth rate in PWS is considered as an indicator of GH deficiency by some authors and provocative $\mathrm{GH}$ testing is not thought to be necessary $(4,6,9)$, provocative tests for $\mathrm{GH}$ deficiency are generally recommended to be performed in PWS patients with inadequate growth rates as well as in those who show adequate growth. Depending on the results of the $\mathrm{GH}$ stimulation tests, $\mathrm{GH}$ treatment is recommended for patients with inadequate, as well as for those with adequate growth rates. The decision should be made together with the family after informing them about the benefits of $\mathrm{GH}$ treatment in detail. Moreover, the diagnosis of PWS needs to be verified by genetic testing before starting treatment with $\mathrm{GH}(9,12,15,16,17)$.

$\mathrm{GH}$ treatment in PWS was first applied in 1990s. Treatment outcomes and benefits for these patients were presented in the national conference of the Prader-Willi Syndrome Association which took place in 1998-1999 in the United States of America (18). The Federal Drug Association approved the use of GH in PWS in 2000 and the treatment has become widespread since. With the experiences gained in the subsequent years, attention has been drawn to the fact that starting treatment at a younger age improved its benefits, particularly its effect on muscle tonus. Nevertheless, no consensus could be reached on age of starting treatment $(12,13,14,15,16)$. However, many researchers consider that starting treatment before the age of 2 years, at a time which coincides with onset of obesity, has a more beneficial effect on clinical improvement. However, this is not always possible, since in many countries, documentation of low growth rate is required to start $\mathrm{GH}$ treatment $(9,12,16,17)$. 


\section{Effects of GH Therapy}

$\mathrm{GH}$ has beneficial effects on linear growth, body composition, basal energy consumption, muscle strength, exercise tolerance, decrease in free fat mass, bone density, lipid profile and physical and cognitive functions $(12,13,14$, $15,19,20,21,22,23,24)$. Age of starting treatment, treatment dose and duration of treatment are the determinants of therapy response $(2,4,9)$. In a study that compared PWS patients receiving $\mathrm{GH}$ therapy with those who did not, it was reported that the group receiving treatment had a lower body fat, increased muscle mass, better lipid profile and better motor function. In that study, the age of starting treatment was 4-20 months and the authors suggested that early treatment might explain the significant differences observed $(13,14,15)$. Many studies revealed that $\mathrm{GH}$ therapy provides significant improvement in body composition and height, particularly in the first year of treatment $(6,9,12,13,14,15)$. In addition to height and body composition, $\mathrm{GH}$ has been reported to have beneficial effect on cognitive functions and behavioral patterns. It has been emphasized that significant improvement is observed in the mobility scores, motor skills, language and cognitive functions of the patients on the development tests performed before treatment and during follow-up $(9,23,24)$.

The results of the Bakker et al's study (25), conducted on 60 PWS patients who began to receive $\mathrm{GH}$ therapy at the age of 3-7 years and were able to continue it for 8 years, are quite important to understand the effects of $\mathrm{GH}$ treatment. This study is unique as it comprises PWS patients who received $\mathrm{GH}$ therapy for the longest period. Whilst the height standard deviation (SD) of the patients was under -2 SD before treatment, all were reported to achieve normal height SD after treatment. Whilst lean body mass significantly increased and fat SD\% significantly decreased in the first year of treatment, no significant difference was observed in the subsequent years and at the end of the 8-year treatment period versus baseline in either of these parameters. The authors attributed these results to the effect of GH therapy in hindering obesity. Nonetheless, BMI values of the cases remained +2 SD above that of normal children but were below that of non-treated children with PWS. Moreover, it was reported that with GH therapy, there was no increase in fasting insulin, homeostasis model assessment of insulin resistance and serum glucose level that no diabetes developed in any of the patients, but that a significant decrease was noted in serum cholesterol and LDL levels.

In a study that compared the final heights in PWS patients who received $\mathrm{GH}$ with those who did not, final height was $171 \pm 8 \mathrm{~cm}$ in boys and $158 \pm 4 \mathrm{~cm}$ in girls in the treatment group, whereas it was $154 \pm 9 \mathrm{~cm}$ in boys and $144 \pm 6 \mathrm{~cm}$ in girls in the group without treatment (26).

\section{Pretreatment Evaluation}

Before starting GH therapy, one should perform anthropometric evaluation and systemic examination including height, height SD score (SDS), body weight, body mass index (BMI) SDS, waist/hip ratio, bone age and pubertal staging assessment. Moreover, central hypothyroidism and adrenal insufficiency should certainly be explored and L-thyroxine therapy should be started in case hypothyroidism is detected. Presence of adrenal insufficiency should be explored by estimation of serum adrenocorticotropic hormone (ACTH)-cortisol levels in blood samples obtained in the early morning and by low-dose ACTH stimulation test when needed $(2,3,4,5,7,8,9,10)$. It has been reported that undetectable adrenal insufficiency might be responsible for mortality during GH therapy in PWS patients. It has also been reported that losing the patients particularly because of infection might be associated with non-use of steroid replacement therapy. Hydrocortisone therapy in stress doses is recommended in moderate and severe infections $(27,28,29)$. In addition, evaluation of growth rate is needed and $\mathrm{GH}$ stimulation tests should be performed in those with as well as without inadequate growth rate. Serum IGF-1 and IGF binding protein-3 (IGFBP-3) levels are important parameters both before treatment and during monitoring. IGF-1 levels should be kept under $+2 \mathrm{SD}$ over the course of treatment period and/or IGF-1/IGFBP-3 ratio should not be allowed to exceed pretreatment level $(2,9,12,13,14,15,23)$. Metabolic status should be evaluated if the patient is older than 12 years, or in the presence of morbid obesity. Fasting blood glucose, fasting insulin and lipid profiles should be assessed and oral glucose tolerance testing (OGTT) should be performed in the presence of additional risks (family history of diabetes or acanthosis nigricans, etc.). Obese patients should undergo AST, ALT testing and abdominal ultrasonography for hepatic steatosis and body composition should be evaluated (DEXA or bioelectrical impedance, if available) $(4,7,9,30)$. The diagnosis of PWS must be verified genetically before treatment $(2,4,7,9,10)$. Diet for PWS patients should be arranged under the supervision of a dietitian both before and over the course of treatment. Inadequate feeding due to hypotonia in infancy unfavorably influences the mental development of these patients. These patients must be fed via gastrostomy if necessary. The struggle against obesity in childhood should include regulation of diet and physical exercises and in conjunction with $\mathrm{GH}$ therapy. For developmental and cognitive evaluation, age-match psychomotor testing should be performed. The patients should be evaluated for motor function and directed for physical therapy, psychotherapy and occupational therapy if necessary $(4,9,12,13,14,15,24,25)$. ENT consultation should be requested if breathing disorders during sleep, snoring, enlarged tonsils and adenoids are present. Tonsillectomy and adenoidectomy should be 
performed if indicated. Presence of sleep apnea should be assessed by polysomnography before starting $\mathrm{GH}$ therapy. It is necessary to perform polysomnographic evaluation at regular intervals over the course of monitoring in patients under treatment $(2,4,7,9,10)$. Presence of scoliosis should be assessed by roentgen graphic imaging of the vertebrae and orthopedic consultation should be requested if indicated $(19,20,31)$. The family should be informed in writing about the benefits and risks of $\mathrm{GH}$ therapy as well as those of careful monitoring. Permission should be obtained for follow-up and treatment from the legal representative of the patient or from the patient him/herself depending on the age and cognitive status of the patient $(4,9)$.

\section{Efficacy of GH Dosage}

The best response to GH in PWS patient is observed in the first 12 months of treatment. Response to $\mathrm{GH}$ therapy changes according to age of starting treatment, degree of growth retardation and duration of treatment. Improvement in linear growth, bone density and body composition continues in those who receive therapy for 5 years. Nevertheless, it has been reported that long-term therapy may always not result in complete improvement in body composition, but stabilization is provided. Although early treatment is important for the improvement in body composition, generally, in practice, it is possible to start treatment only after age 2 years $(9,12,13,14$, $15,19,20,21,22,23,24,32)$

Treatment can be started in a dose of $0.034 \mathrm{mg} / \mathrm{kg} /$ day $(0.24 \mathrm{mg} / \mathrm{kg} /$ week) in infants and toddlers. IGF-1 and IGFBP-3 levels are used to specify the dose of GH therapy. The dose can be increased up to $1 \mathrm{mg} / \mathrm{m}^{2} /$ day so that IGF-1 levels are between the ranges $+1 \mathrm{SD}$ and $+2 \mathrm{SD}$ depending on age $(2,7,9,33)$. The dose can be decreased if serum IGF-1 level increases over $+2 \mathrm{SD}$.

Benefits of continuing $\mathrm{GH}$ therapy in adulthood remains unclear. However, a moderate improvement has been observed in body composition and cognitive functions in PWS patients who received treatment in adulthood but not in childhood, suggesting that beneficial effects are still present even after the epiphyses are fused $(26,33,34)$. Similar to the dose used for $\mathrm{GH}$ deficiency in adults, a daily dose of 0.1-0.2 $\mathrm{mg}$ is recommended; it should be adjusted so that the IGF-1 level is maintained between 0 SDS and - 2 SDS to reduce the probability of adverse events $(7,9,26,33,34)$.

\section{Contraindications to $\mathbf{G H}$ Treatment}

Severe obesity, uncontrolled diabetes mellitus, untreated severe OSA, active cancer and psychosis are the accepted contraindications for $\mathrm{GH}$ therapy in PWS patients $(2,4,7,9)$.

\section{Adverse Events and Safety}

As true for other patients receiving $\mathrm{GH}$, patients with PWS should be monitored for potential adverse events by periodic complete blood count, thyroid function evaluation and evaluation of glucose metabolism. In addition, with the prediction that $\mathrm{GH}$ therapy will enhance adenotonsillar hypertrophy in PWS, the patients should be questioned for shortness of breath, snoring and sleep apnea and, if necessary, should be evaluated via polysomnography on the $3^{\text {rd }}$ and $6^{\text {th }}$ months after treatment. It should be kept in mind during monitoring that glucose metabolism disorders and type 2 diabetes are expected to be more common in PWS patients due to concomitant obesity. However, it has been reported that $\mathrm{GH}$ treatment showed no adverse effects on glucose parameters and lipid profile in PWS patients (26). Scoliosis and femur head epiphysis dislocation need to be explored at each control visit. Serum IGF-1 level should be kept under $+2 \mathrm{SD}$ and it is necessary to decrease the treatment dose in cases with higher levels. In patients with high serum IGF-1 levels, an effort should be made to keep the IGF-1/IGFBP-3 ratio at the same level as the baseline $(9,26,34)$.

Worldwide, 28 deaths have been reported among PWS patients who had been receiving $\mathrm{GH}$. Common characteristics of these patients were that they generally died due to respiratory problems or respiratory system infections in the first 9 months of treatment and that these patients were morbid obese $(7,9,28,35)$. Although respiratory complications are seen in the first 3 months of $\mathrm{GH}$ therapy in patients with morbid obesity, these adverse events are also reported in the majority of the children. Indeed, mortality rate is reported to be high in PWS, but it has not been possible to establish a direct association between deaths and $\mathrm{GH}$ treatment. Moreover, no difference was found in mortality rates between the groups receiving treatment and those who were not. An increase in risk of sudden death has been reported in children with PWS, independent of $\mathrm{GH}$ therapy $(28,35,36,37,38)$.

Whilst GH therapy leads to adenotonsillar hypertrophy and obstructive apnea on the one hand, on the other hand, it improves central hypoventilation via direct effect on hypothalamic function $(9,19,20,21,32,35)$. Improvement was demonstrated in respiratory disorders and respiratory functions via this mechanism in cases with high IGF-1 levels $(7,8,9,37)$. In view of all this information, it is recommended that treatment should be started after adenotonsillar surgery in children who have obstructive apnea before treatment; that steroid replacement therapy should be given in stress doses for infections that develop during treatment; that GH therapy should be stopped until the infection has subsided; and that $\mathrm{GH}$ therapy should be discontinued in the event of a new upper respiratory obstruction and/or sleep apnea which has developed after the onset of treatment for the first time $(4,9)$.

The patient should be monitored periodically over the course of GH therapy. Polysomnography and ear-nose-throat examination should be performed on the $6^{\text {th }}$ week, $3^{\text {rd }}$ 
month and on the $6^{\text {th }}$ month of treatment and whenever necessary $(9,14)$. Fasting blood glucose, OGTT, IGF-1, free thyroxine and thyroid-stimulating hormone testing should be performed on the first month of treatment and/or whenever necessary and orthopedic examination and X-ray imaging of the spine should be performed in case of necessity $(4,7,9,10,14,25)$.

In conclusion, $\mathrm{GH}$ treatment therapy appears to be of benefit in selected cases of PWS, provided that these patients are monitored carefully and precisely. Diet and physical activity should continue over the course of treatment. It will be reasonable to discontinue the treatment in the presence of infection and respiratory obstruction. Steroid replacement in stress doses needs to be given in case of infections.

\section{References}

1. Prader A, Labhart A, Willi A. Ein syndrom von adipositas, kleinwuchs, kryptorchismus und oligophrenie nach myotonie artigen zustand im neugeborenenalter. Schweiz Med Wochen 1956;86:1260.

2. Cassidy SB, Schwartz S, Miller JL, Driscoll DJ. Prader-Willi syndrome. Genet Med 2012;14:10-26.

3. Butler MG. Prader-Willi syndrome: obesity due to genomic imprinting. Curr Genomics 2011;12:204-215.

4. Goldstone $A P$, Holland AJ, Hauffa BP, Hokken-Koelega AC, Tauber $M$; speakers contributors at the Second Expert Meeting of the Comprehensive Care of Patients with PWS. Recommendations for the diagnosis and management of Prader-Willi syndrome. J Clin Endocrinol Metab 2008;93:4183-4197. Epub 2008 Aug 12

5. McCandless SE; Committee on Genetics. Clinical reporthealth supervision for children with Prader-Willi syndrome. Pediatrics 2011;127:195-204. Epub 2010 Dec 27

6. Diene G, Mimoun E, Feigerlova E, Caula S, Molinas C, Grandjean H, Tauber M; French Reference Centre for PWS. Endocrine disorders in children with Prader-Willi syndromedata from 142 children of the French database. Horm Res Paediatr 2010;74:121-128. Epub 2010 Apr 15

7. Emerick JE, Vogt KS. Endocrine manifestations and management of Prader-Willi syndrome. Int $\mathrm{J}$ Pediatr Endocrinol 2013;2013:14.

8. Bekx MT, Carrel AL, Shriver TC, Li Z, Allen DB. Decreased energy expenditure is caused by abnormal body composition in infants with Prader-Willi syndrome. J Pediatr 2003;143:372-376.

9. Deal $C L$, Tony $M$, Höybye $C$, Allen $D B$, Tauber $M$, Christiansen JS; 2011 Growth Hormone in Prader-Willi Syndrome Clinical Care Guidelines Workshop Participants. Growth Hormone Research Society work shop summary: consensus guidelines for recombinant human growth hormone therapy in Prader-Willi syndrome. J Clin Endocrinol Metab 2013;98:1072-1087. Epub 2013 Mar 29

10. Burman P, Ritzén EM, Lindgren AC. Endocrine dysfunction in Prader-Willi syndrome: a review with special reference to GH. Endocr Rev 2001;22:787-799.

11. Eiholzer U, Stutz K, Weinmann C, Torresani T, Molinari L, Prader A. Low insulin, IGF-I and IGFBP-3 levels in children with Prader-Labhart-Willi syndrome. Eur J Pediatr 1998;157:890-893.
12. Grugni G, Crinò A, Pagani $S$, Meazza $C$, Buzi F, De Toni $T$, Gargantini L, Pilotta A, Pozzan GB, Radetti G, Ragusa L, Salvatoni A, Sartorio A, Bozzola M; Genetic Obesity Study Group, Italian Society of Pediatric Endocrinology and Diabetology. Growth hormone secretory pattern in nonobese children and adolescents with Prader-Willi syndrome. J Pediatr Endocrinol Metab 2011:24:477-481.

13. Carrel AL, Myers SE, Whitman BY, Eickhoff J, Allen DB. Long-Term Growth Hormone Therapy Changes the Natural History of Body Composition and Motor Function in Children with Prader-Willi Syndrome. J Clin Endocrinol Metab 2010;95:1131-1136. Epub 2010 Jan 8

14. Fillion M, Deal C, Van Vliet G. Retrospective study of the potential benefits and adverse events during growth hormone treatment in children with Prader-Willis syndrome. J Pediatr 2009;154:230-233. Epub 2008 Sep 23

15. Siemensma EP, Tummers-de Lind van Wijngaarden RF, Festen DA, Troeman ZC, van Alfen-van der Velden AA, Otten BJ, Rotteveel J,Odink RJ, Bindels-de Heus GC, van Leeuwen M, Haring DA, Oostdijk W, Bocca G, Mieke Houdijk EC, van Trotsenburg AS, Hoorweg-Nijman JJ, van Wieringen $H$, Vreuls RC, Jira PE, Schroor EJ, van PinxterenNagler E, Willem Pilon J, Lunshof LB, Hokken-Koelega AC. Beneficial effects of growth hormone treatment on cognition in children with Prader-Willi syndrome: a randomized controlled trial and longitudinal study. J Clin Endocrinol Metab 2012;97:2307-2314. Epub 2012 Apr 16

16. Feigerlová E, Diene G, Oliver I, Gennero I, Salles JP, Arnaud $C$, Tauber M. Elevated insulin-like growth factor-I values in children with Prader-Willi syndrome compared with growth hormone $(\mathrm{GH})$ deficiency children over two years of $\mathrm{GH}$ treatment. J Clin Endocrinol Metab 2010;95:4600-4608.

17. van Nieuwpoort IC, Sinnema M, Castelijns JA, Twisk JW, Curfs LM, Drent ML. The GH/IGF-I axis and pituitary function and size in adults with Prader-Willi syndrome. Horm Res Paediatr 2011;75:403-411. Epub 2011 Jan 27

18. Growth Hormone and Prader Willi Syndrome. 2th ed. Editor Donald G Goranson 2011:7-8.

19. de Lind van Wijngaarden RF, Siemensma EP, Festen DA, Otten BJ, van Mil EG, Rotteveel J, Odink RJ, Bindels-de Heus GC, van Leeuwen M, Haring DA, Bocca G, Houdijk EC, Hoorweg-Nijman JJ, Vreuls RC, Jira PE, van Trotsenburg AS, Bakker B, Schroor EJ,Pilon JW, Wit JM, Drop SL, HokkenKoelega AC. Efficacy and safety of long-term continuous growth hormone treatment in children with Prader-Willi syndrome. J Clin Endocrinol Metab 2009;94:4205-4215. Epub 2009 Oct 16

20. Höybye C, Thorén M, Böhm B. Cognitive emotional, physicaland social effects of growth hormone treatment in adults with Prader-Willi syndrome. J Intellect Disabil Res 2005;49:245-252.

21. Mogul HR, Lee PD, Whitman BY, Zipf WB, Frey M, Myers S, Cahan M, Pinyerd B, Southren AL. Growth hormone treatment of adults with Prader-Willi syndrome and growth hormone deficiency improves lean body mass, fractional body fat and serum triiodothyronine without glucose impairment: results from the United States multicenter trial. J Clin Endocrinol Metab 2008;93:1238-1245. Epub 2008 Jan 22

22. Lee PD, Wilson DM, Rountree L, Hintz RL, Rosenfeld RG. Linear growth response to exogenous growth hormone in Prader-Willi syndrome. Am J Med Genet 1987;28:865-871.

23. Myers SE, Whitman BY, Carrel AL, Moerchen V, Bekx MT, Allen DB. Two years of growth hormone therapy in young children with Prader-Willi syndrome: physical and neurodevelopmental benefits. Am J Med Genet A 2007;143:443-448. 
24. Festen DA, Wevers $M$, Lindgren AC, Böhm B, Otten BJ, Wit JM, Duivenvoorden HJ, Hokken-Koelega AC. Mental and motor development before and during growth hormone treatment in infants and toddlers with Prader-Willi syndrome. Clin Endocrinol (Oxf) 2008;68:919-925. Epub 2007 Nov 19

25. Bakker NE, Kuppens RJ, Siemensma EP, Tummers-de Lind van Wijngaarden RF, Festen DA, Bindels-de Heus GC, Bocca G, Haring DA, Hoorweg-Nijman JJ, Houdijk EC, Jira PE, Lunshof L, Odink RJ, Oostdijk W, Rotteveel J, Schroor EJ, Van Alfen AA, Van Leeuwen M, Van Pinxteren-Nagler $\mathrm{E}$, Van Wieringen $\mathrm{H}$, Vreuls RC, Zwaveling-Soonawala $\mathrm{N}$, de Ridder MA, Hokken-Koelega AC. Eight years of growth hormone treatment in children with prader-willi syndrome: maintaining the positive effects. J Clin Endocrinol Metab 2013;98:4013-4022. Epub 2013 Sep 3

26. Angulo MA, Castro-Magana M, Lamerson M, Arguello $R$, Accacha $S$, Khan A. Final adult height in children with Prader-Willi syndrome with and without human growth hormone treatment. Am J Med Genet A 2007;143:14561461.

27. Nagai T, Obata $K$, Tonoki $H$, Temma $S$, Murakami $N$, Katada Y, Yoshino A, Sakazume S, Takahashi E, Sakuta R, Niikawa N. Cause of sudden, unexpected death of PraderWilli syndrome patients with or without growth hormone treatment. Am J Med Genet A 2005;136:45-48.

28. Tauber M, Diene G, Molinas C, Hébert M. Review of 64 cases of death in children with Prader-Willi syndrome (PWS). Am J Med Genet A 2008;146:881-887.

29. de Lind van Wijngaarden RF, Otten BJ, Festen DA, Joosten $\mathrm{KF}$, de Jong $\mathrm{FH}$, Sweep FC, Hokken-Koelega AC. High prevalence of central adrenal insufficiency in patients with Prader-Willi syndrome. J Clin Endocrinol Metab 2008;93:1649-1654. Epub 2008 Feb 26

30. de Lind van Wijngaarden RF, Festen DA, Otten BJ, van Mil EG, Rotteveel J, Odink RJ, van Leeuwen M, Haring DA, Bocca G, Mieke Houdijk EC, Hokken-Koelega AC. Bone mineral density and effects of growth hormone treatment in prepubertal children with Prader-Willi syndrome: a randomized controlled trial. J Clin Endocrinol Metab 2009;94:3763-3771. Epub 2009 Jul 21

31. de Lind van Wijngaarden RF, de Klerk LW, Festen DA, Duivenvoorden $\mathrm{HJ}$, Otten BJ, Hokken-Koelega AC.
Randomized controlled trial to investigate the effects of growth hormone treatment on scoliosis in children with Prader-Willi syndrome. J Clin Endocrinol Metab 2009;94:1274-1280. Epub 2009 Jan 21

32. Grugni G, Crinò A, Bosio L, Corrias A, Cuttini M, De Toni T, Di Battista E, Franzese A, Gargantini L, Greggio N, lughetti L, Livieri C,Naselli A, Pagano C, Pozzan G, Ragusa L, Salvatoni A, Trifirò G, Beccaria L, Bellizzi M, Bellone J, Brunani $A$, Cappa M, Caselli G,Cerioni V, Delvecchio M, Giardino D, lannì F, Memo L, Pilotta A, Pomara C, Radetti G, Sacco M, Sanzari A, Sartorio A, Tonini G, Vettor R,Zaglia F, Chiumello G; Genetic Obesity Study Group of Italian Society of Pediatric Endocrinology and Diabetology (ISPED). The Italian National Survey for Prader-Willi syndrome: an epidemiologic study. Am J Med Genet A 2008;146:861-872.

33. Sode-Carlsen R, Farholt S, Rabben KF, Bollerslev J, Schreiner T, Jurik AG, Christiansen JS, Höybye C. One year of growth hormone treatment in adults with Prader-Willi syndrome improves body composition: results from a randomized, placebo-controlled study. J Clin Endocrinol Metab 2010;95:4943-4950. Epub 2010 Aug 11

34. Höybye $C$, Hilding A, Jacobsson $H$, Thorén M. Growth hormone treatment improves body composition in adults with Prader-Willi syndrome. Clin Endocrinol (Oxf) 2003;58:653-661.

35. Bakker B, Maneatis T, Lippe B. Sudden death in Prader-Willi syndrome: brief review of five additional cases. Concerning the article by $U$. Eiholzer et al.: Deaths in children with Prader-Willi syndrome. A contribution to the debate about the safety of growth hormone treatment in children with PWS (Horm Res 2005;63:33-39). Horm Res 2007;67:203204. Epub 2006 Dec 12

36. Nordmann Y, Eiholzer U, I'Allemand D, Mirjanic S, Markwalder C. Sudden death of an infant with Prader-Willi syndrome not a unique case? Biol Neonate 2002;82:139-142.

37. Eiholzer U, Nordmann Y, L'Allemand D. Fatal outcome of sleep apnoea in PWS during the initial phase of growth hormone treatment. A case report. Horm Res 2002;58(Suppl 3):24-26.

38. Van Vliet G, Deal CL, Crock PA, Robitaille Y, Oligny LL. Sudden death in growth hormone-treated children with Prader-Willi syndrome. J Pediatr 2004;144:129-131. 